\title{
Reliability and Validity of Self-Reported Questionnaires Related to Adolescent Violence and Consequences, Thailand
}

\author{
Nualnong Wongtongkam ${ }^{1,2}$, Paul Russell Ward ${ }^{2}$, Andrew Day ${ }^{3}$, Anthony Harold Winefield ${ }^{4}$ \\ ${ }^{1}$ School of Biomedical Sciences, Charles Sturt University, New South Wales, Australia \\ ${ }^{2}$ Discipline of Public Health, Faculty of Health Sciences, Flinders University, South Australia, Australia \\ ${ }^{3}$ Faculty of Health, School of Psychology, Deakin University, Victoria, Australia \\ ${ }^{4}$ School of Psychology, Social Work and Social Policy, University of South Australia, South Australia, Australia \\ Correspondence: Nualnong Wongtongkam, School of Biomedical Sciences, Charles Sturt University, Panorama \\ Avenue, Bathurst, New South Wales, 2795, Australia. Tel: 62-6338-4309. E-mail: nwongtongkam@csu.edu.au
}

Received: March 22, 2013 Accepted: May 22, 2013 Available online: June 1, 2013

doi:10.11114/ijsss.v1i2.110 URL: http://dx.doi.org/10.11114/ijsss.v1i2.110

\begin{abstract}
In Thailand physical violence among male adolescents is considered a significant public health issue, although there has been little published research into the aetiology and functions of violence in Thai youth. Research in this area has been hampered by a lack of psychometrically sound tools that have been validated to assess problem behaviours in Asian youth. The purpose of this paper is to provide validity and reliability data on an instrument to measure violence in Thai youth. In this study, reliability and validity data for a sample of adolescent Thai youth are reported for the Communities That Care Youth Survey (CTC-YS), a measure of risk and protective factors for violent behaviour, and the STAXI-II, a measure of angry experience and expression. The findings showed overall high internal consistency for both questionnaires, and there was evidence of construct validity. It is concluded that these measures are appropriate for use in research that seeks to investigate youth violence among adolescents in Thailand.
\end{abstract}

Keywords: Adolescence, Violence, CTC-YS, STAXI-II; Thailand

\section{Introduction}

Violence perpetrated by young people is a significant social and public health issue in many countries around the world (Reza, Krug, \& Mercy, 2001) which is typically understood as a product of individual, friend, family, community and school risk and protective factors (see Krug, Mercy, Dahleberg, \& Zwi, 2002; Le, Monfared \& Stockdale, 2005). However, those measures that have been widely used to assess these factors have been developed using African-American and European-American samples (Smith \& Krohn, 1995; Thornberry, Lizotte, Krohn, Farnworth, \& Jang, 1991) and their applicability to other ethnic and racial groups has not been well-established. Accordingly the aim of this study is to report preliminary data on the internal consistency and validity of two of the most widely used self-report assessments in research on aggressive and behaviour behaviour in a sample of Thai youth.

In Thailand physical violence among adolescents is of particular concern. The need to identify valid measures of violence risk factors is of particular importance given that violence in Thailand may be qualitatively different from that which occurs in Western cultures. For example, Thai males may be more likely to carry weapons (Ruangkanchanasetr, Plitponkarnpim, Hetrakul, \& Kongsakon, 2005), and routinely engage in fights, especially in technical colleges where 90\% of students are men (Vocational Education Commission, 2010).

One self-report measure that has been used in Thailand is the Youth Risk Behaviour Surveillance System (YRBS) (Assanangkornchai, Pattanasattayawong, Samangsri, \& Mukthong, 2007; Ruangkanchanasetr et al., 2005) which, although assessing many aspects of risk taking behaviour, does not specifically assess violence. The YRBS consists of six categories of behaviours, including behaviours that contribute to unintentional injuries and violence, tobacco use, alcohol and other drug use, sexual behaviour contributing to unintended pregnancy and sexually transmitted disease, unhealthy dietary behaviours, and inadequate physical activity (Centers for Disease 
Control and Prevention, 2003). The Communities That Care Youth Survey (CTC-YS) purports to assess a broad range of risk and protective factors across multiple domains, and as such appears to be particularly valuable in identifying those risk and protective factors that might be target in violence prevention efforts. The CTC-YS has been shown to reliably predict behavioural problems during adolescence (Hawkins et al., 1995), but has not previously been validated for use with Asian populations. Similarly, the serious delinquency instrument and violence classification (offenders, victims, and witnesses) questionnaires have shown good reliability and validity in young Americans (Loeber et al., 2003) but as far as we know, the scales have never been tested in Thailand or other Asian countries.

Spielberger's (1999) State-Trait Anger Expression Inventory-2 (STAXI-II) is a measure of anger experience and expression that is also used to assess aggression and violence, given the close association between anger dysregulation and aggressive and violent behaviour. The STAXI-II is one of the most widely used anger measures in both clinical and research settings (Novaco \& Taylor, 2004), and there is psychometric support for its use with different cultures, including both Asian (Bishop \& Quah 1998; Ghos \& Sharma 2006) and Western populations (Lindqvist, Daderman, \& Hellstrom, 2003; Miguel-Tobal, Casado, Cano-Vindel, \& Spielberger, 2001; Muller, Bongard, Heiligtag, \& Hodapp, 2001). However, this instrument has not previously been used in Thailand. The evaluation of anger and violence scales is necessary for many professionals who deal with delinquency behaviours: a valid method for assessing aspect of anger would be of inestimable value when working with perpetrators, victims and witnesses. This study therefore aims to assess the internal consistency, test-retest reliability, and validity of these two self-report scales in a sample of Thai male adolescents.

\section{Method}

\subsection{Participants}

A convenience sample of 32 voluntary male participants was recruited from three college departments (Electrical-Power, Building Construction and Mechanical) offering the Vocational Educational Certificate, Year Level I-III in Thailand. Forty participants were originally recruited, but data from eight participants were subsequently removed from the final sample as over $50 \%$ of their responses were missing. The majority of students were Year-II $(62.50 \%)$, totally males $(100 \%)$, and ages $16.59 \pm 0.80$ (Means \pm S.D.). Most parents worked as unskilled workers, ranging from $86.21 \%$ to $92.59 \%$, but they gave pocket money to their children around US \$ 4 which was a normal rate for school children in Thailand (Table 1.)

Table 1. Demographic data

\begin{tabular}{lcc}
\hline \multicolumn{1}{c}{ Descriptive Data } & \multicolumn{2}{c}{ Number (\%) } \\
\hline Year Levels & & \\
- Year I & $12(37.50)$ & \\
- Year II & $20(62.50)$ & \\
Ages (Years) & $1(3.13)$ & \\
- $\quad 15$ & $15(46.88)$ & \\
- $\quad 16$ & $13(40.63)$ & \\
- $\quad 17$ & $2(6.25)$ & \\
- $\quad 18$ & $1(3.13)$ & \\
Mean \pm S.D. & $16.59 \pm 0.80$ & \\
Father's Occupation & & Missing data 3 (9.40) \\
- Unskilled Jobs & $25(86.21)$ & \\
- Own Business & $1(3.45)$ & \\
- Government Officials & $3(10.34)$ & \\
Mother's Occupation & & Missing data 5 (15.62) \\
- Unskilled Jobs & $25(92.59)$ & \\
- Governmental Officials & $1(3.70)$ & \\
- Housewives & $1(3.70)$ & \\
Pocket Money per day & & \\
Mean \pm S.D. & $116.56 \pm 82.21$ & \\
Median & 100.00 &
\end{tabular}




\subsection{Translations}

The translation followed an established forward-backward translation procedure (McDermont \& Palchanes, 1994) carried out by three experts on youth development and behaviour who had fluency in both English and Thai languages. The back translation was operated by two English teachers who had worked at high schools in Thailand for more than 5 years and who were familiar with Thai culture. Then, the first researcher compared the equivalence of the English version and back-translation version, and agreement was sought between the three experts, the English teachers, and the principal researcher in order to ascertain the readability, clarity, and understandability of the translated version.

The research was publicised by teachers, and students who were interested then contacted the first researcher by e-mail. The questionnaire was sent to the same participants at two points in time, Time one (T1) and Time two (T2), 2 weeks apart in order to establish test-retest reliability. Each participant was reimbursed the equivalent of US $\$ 5$ for his time and expertise. The study was approved by a university research ethics committee.

\subsection{Validity Testing}

Content validity was assessed after considering the findings of an extensive review of the literature on all self-report measures (CTC-YS, STAXI-II, Violence Behaviours and Violence Classification), and then discussing it with experts in the field (two police officials and one forensic staff member). Some items of the items were revised according to appropriate Thai circumstances, particularly in relation to the CTC-YS and violence classification and violence behaviours.

Convergent validity was used to test the degree to which any two instruments (CTC-YS and violence behaviours) are related to each other within similar concepts. Individual risk behaviours from CTC-YS and the violence behaviours were assessed by correlation coefficient Two scales asking about 'ever having been involved in illegal activities' each comprised 8 items on the CTC-YS and there were 4 items on the violence behaviours scale.

In order to assess criterion-related validity, Spearman's rho correlations were calculated to determine the strength of the CTC-YS, violence behaviours and violence classification scales' relationship with criterion measures, and to measure intercorrelations among scales. Nonparametric correlations were utilised because of non-normal distribution of all scales.

\subsection{Reliability Testing}

Internal consistency reliability was assessed using Cronbach's alpha. Spearman's rho correlation was used to assess each instruments test-retest reliability. Correlation coefficients of $>0.68,0.36$ to 0.67 , and $<0.35$ were considered to be strong, moderate, or weak, respectively (Taylor, 1990).

\section{Instruments}

\subsection{Risk and Protective Domains}

Items in the CTC-YS measure 21 risk factor and 11 protective factor constructs (Developmental Research and Programs, 1996) based on adolescents' drug use, delinquency, and violence (Hawkins et al. 1998). Individual, family, peer, school, and community-level risk and protective factors are all measured. Most risk factor items are rated on a 4 point-scale ('definitely not true', 'mostly not true', 'mostly true', and 'definitely true'). Exceptions were community norms favourable to drug use ('very wrong' to 'not wrong at all'); perceived availability of drugs ('very hard' to 'very easy'); perceived availability of drugs ('very hard' to 'very easy') to a 4-point scale, and binge drinking was scored as a dichotomous variable (' $1=$ ever' and ' $0=$ never'). One item asked whether they had have ever used smokeless tobacco but frequent use of smokeless tobacco item was deleted resulting from low prevalence of smokeless tobacco use in Thailand (Centers for Disease Control and Prevention, 2010). Additionally, drugs (debisol, heroin, LSD, pain relievers, tranquilizers, and stimulants drugs) were removed because there are no previous reports showing that Thai adolescents have access to these drugs. All protective factors were rated on a 4-point scale and for most scales response options ranged from 'definitely yes' to 'definitely no'. A complete list of items included in each of the risk and protective factor scales is available in previous publications (Arthur et al., 2002; Glaser et al., 2005; Pollard, Hawkins, \& Arthur, 1999) or by request from the corresponding author.

\subsection{Anger Expression.}

The State-Trait Anger Expression Inventory (STAXI-2) scale is a 32-item questionnaire developed to measure characteristic styles of anger arousal. Participants are asked to rate the frequency with which they engaged in the items when feeling angry across a four-point Likert-type scale ranging from 1 (almost never) to 4 (almost always) 
(Spielberger, 1999) .The four eight-item subscales assess anger-in, anger-out, anger control-in, and anger control-out, respectively. The scale has been widely use to measure anger in college students and has been shown to have acceptable reliability, and validity (Culhane \& Morea, 2010; Garcia-Leon et al., 2002).

\subsection{Violent Behaviour}

The serious violence measure was based on the Pittsburgh Youth Study's measure of serious violence (Loeber et al., 2003). The original self-reported serious violence measure consists of five items: aggravated assault; two robber items; rape; and gang fights. With the modified scale, the item about hurting or threatening to hurt someone to get them to have sex was deleted, but an item remained asking about trying to have a sexual relationship with someone against their will, also the item asking about killing someone was removed. Hence, this scale comprised only four items. The violence activities were to be assessed over the previous 6 months, and response categories with 6-point Likert Scale were 0 (0), 1-2 times (1), 3-5 times (2), 6-9 times (3), 10-19 times (4) to 20 or more times (5), respectively.

\subsection{Victims, Witnesses and Perpetrators}

A self-report measure of victimisation was modified from the SEQ-SR (Crick \& Grotpeter, 1996), by assessing only 11 items (direct and indirect victimization) from 15 items, with a 6-point Likert-type scale. Items relating to receipt of prosocial behaviours were removed. Victimization was divided into two types: overt and relational. Overt or direct victimization refers to being the target of aggressive actions by peers, including physical aggression. Relational or indirect victimization refers to being the object of aggressive actions designed to damage relationships and social status (Bauman \& Summers, 2009).

Witnessing violence was assessed by six items asking whether or not respondents had seen someone being beaten up or mugged, threatened with serious physical harm by someone, shot, or shot at with a gun, attacked or stabbed with a knife, chased by gangs or individuals, or serious wounded in an incident of violence, with 6-point Likert-type scale from 0 (0) to 20 or more times (5).

Violent offenses asked whether they had been involved in attempting to cause harm to others (Lennings, Copeland \& Howard, 2003). The self-report questionnaire was a slightly modified version of overt victimization from the Problem Behaviour Frequency Scale (Orapins \& Kelder, 1995) in 5 items, which asked respondents whether they have hit, pushed or shoved, threatened to hit, yelled or called mean names, threatened or injured to someone with a weapon (gun, knife, club, etc), over the past 6 months. The responses with 6-point Likert Scale ranged from 0 (0) to 20 or more times (5).

\section{Results}

All self-report scales were analysed using SPSS Version 17.0 (SPSS Inc., Chicago, IL) with a 5\% level of significance.

Internal consistency reliability was assessed by Cronbach's alpha for four domains (School, Peer and Individual, Community, and Family) on the CTC-YS index, all of which showed overall high alpha coefficients. Values above 0.7 indicate acceptable reliability (Cronbach, 1951). Internal consistency was 0.87 on School, with 0.92 on Peer and Individual, with 0.91 on Community, and with 0.95 on Family domains. The internal consistency was less than 0.70 on the low commitment scale (Risk Factor) for School domain, with social skill subscale (Protective Factor) for Peer and Individual, with Community rewards for prosocial involvement (Protective Factor), as presented in Table 2. The overall alpha for the STAXI-II scale was 0.90 , although it was only 0.62 for the Anger-In subscale (Table 3).

Table 2. Internal Consistency among protective and risk factor on CTC-Youth Survey self-report

\begin{tabular}{lcc}
\hline \multicolumn{1}{c}{ Domain } & Items & Cronbach Alpha \\
\hline $\begin{array}{l}\text { School } \\
\text { Protective Factor }\end{array}$ & 17 & 0.87 \\
$\begin{array}{l}\text { Pchool opportunities for prosocial involvement } \\
\text { School rewards for prosocial involvement }\end{array}$ & 5 & 0.78 \\
Risk Factors & 4 & 0.81 \\
- Low Commitment & 7 & 0.63 \\
- Poor Academic Performance & 1 & N/A \\
Peer and Individual & & \\
\hline
\end{tabular}


\begin{tabular}{ll}
\hline$\quad$ Overall & 61 \\
Protective Factor &
\end{tabular}

- Religiosity

- Belief in the moral Order

0.92

- Social skills

- Interaction with prosocial peers

Risk Factors

- $\quad$ Friends' use of drugs

- Friends' delinquent behaviours

- Peer rewards for antisocial behaviours

N/A

- Early initial of drug use

$\begin{array}{ll}8 & 0.93 \\ 4 & 0.48\end{array}$

- Rebelliousness

0.90

- Sensational seeking

- Favourable Attitudes towards antisocial behaviours

5

0.80

Favourable Attitudes towards of drug uses

- Low perceived risk of drug uses

$\begin{array}{ll}7 & 0.82 \\ 4 & 0.69\end{array}$

$\begin{array}{ll}4 & 0.69 \\ 9 & 0.78\end{array}$

$3 \quad 0.77$

$3 \quad 0.92$

$5 \quad 0.82$

$4 \quad 0.76$

Community

- Overall

0.95

Protective Factors

- Community rewards for prosocial involvement

0.91

- Community opportunities for prosocial involvement

Risk Factors

- $\quad$ Perceived availability of drugs

- Perceived availability of firearm

- Laws and norms favourable to drug uses

- Low neighbourhood attachment

30

0.91

$4 \quad 0.64$

- Community disorganisation

- Transition and Mobility

0.89

Family

- Overall

$\begin{array}{ll}1 & \text { N/A } \\ 6 & 0.80\end{array}$

$\begin{array}{ll}6 & 0.92\end{array}$

$5 \quad 0.86$

$5 \quad 0.73$

Protective Factor

- Family rewards for prosocial involvement

- Family attachment

- Family opportunities for prosocial involvement

$\begin{array}{ll}4 & 0.86 \\ 4 & 0.92\end{array}$

Risk Factors

- Family History of antisocial behaviours $\quad 9 \quad 0.77$

- Parental attitudes favourable toward drug uses $\quad 3 \quad 0.79$

- Parental attitudes favourable toward antisocial behaviours $\quad 3 \quad 0.85$

- Poor family management

0.89

- Family conflict

0.79

N/A : Not Applicable.

Table 3. Internal Consistency of Psychological Measurements (Anger), Violence Behaviours and Violence Classification.

\begin{tabular}{|c|c|c|}
\hline Instruments & Items & Cronbach Alpha \\
\hline \multicolumn{3}{|l|}{ STAXI-II (Anger ) } \\
\hline Overall & 32 & 0.90 \\
\hline - $\quad$ Anger Out & 8 & 0.79 \\
\hline - $\quad$ Anger-In & 8 & 0.62 \\
\hline - Anger Control-Out & 8 & 0.80 \\
\hline - $\quad$ Anger Control-In & 8 & 0.80 \\
\hline $\begin{array}{l}\text { Violence Behaviours } \\
\text { Violence Classification }\end{array}$ & 4 & 0.73 \\
\hline $\begin{array}{ll}\text { - } & \text { Offenders } \\
\text { - } & \text { Victims }\end{array}$ & 6 & 0.94 \\
\hline
\end{tabular}




\begin{tabular}{lcll}
\hline- & Indirect & 5 & 0.74 \\
- & Direct & 6 & 0.85 \\
- & Witnesses & 5 & 0.89 \\
\hline
\end{tabular}

With regard to the violence indices, all subscales of violence behaviours and violence classification (offenders, victims and witnesses) revealed high internal consistency reliability coefficients with the highest on the offenders scale (0.94), as shown in Table 3.

Convergent validity showed a low intercorrelation $r_{s}(30)=0.36$ between Risk Behaviour subscale within CTC-YS and violence behaviours although it was statistically significant, $p<.05$. In order to assess criterion validity, intracorrelations within subscales and intercorrelations between two measures (Violence Behaviours and Violence Classification and STAXI-II) were calculated using Spearman's rho. Within subscales, violence behaviours and violence classification measures displayed high correlations across all subscales with statistical significance $(p<.05)$. Violence behaviours had a strong correlation with offenders, $r_{s}(30)=0.85$, and offenders was highly correlated with direct victims, $r_{s}(30)=0.66$. Witnesses and direct victims correlated highly, $r_{s}(30)=$ 0.78. Regarding CTC-YS, the protective and risk factors were summed within each domain. The school domain displayed significant intracorrelations with Peer - Individual and Community scales, and Peer and Individual indices also correlated with Community and Family (Table 4).

Table 4. Spearman rho correlations among CTC Youth Survey domains

\begin{tabular}{lllll}
\hline Domains & School & Peer and Individual & Community & Family \\
\hline School & 1.00 & $0.41^{*}$ & $0.37^{*}$ & 0.25 \\
Peer and Individuals & - & - & $0.73^{*}$ & $0.80^{*}$ \\
Community & - & - & - & $0.75^{*}$ \\
\hline
\end{tabular}

$* p<.05$

Of the STAXI-II subscales, Anger-Out scale showed a strong correlation with only the Anger-In subscale, similarly the Anger-Control out subscale was high correlated with the Anger Control- In subscale, $r_{s}(30)=0.65$, as shown in Table 5. Also, the intercorrelation of each subscale within two measurements (Anger expression and Violence Behaviours), violence behaviours scale showed a moderate correlation with reverse trend with the Anger-In subscale. $r_{s}(30)=-0.38$. Likewise, witnesses subscale displayed a revese correlation with the Anger-In, $r_{s}(30)=-0.38$, and with Anger Control-In subscale. $r_{s}(30)=-0.36$, all $p s<.05$. The Anger Out subscale was moderately correlated with Direct and Indirect victims, $r_{s}(30)=0.41$, and $r_{s}(30)=0.37$, respectively, both $p$ s $<.05$, as shown in Table 5 .

Table 5. Spearman rho correlations between Violence Behaviours and Violence Classification and STAXI-II instruments

\begin{tabular}{|c|c|c|c|c|c|c|c|c|c|}
\hline & \multicolumn{4}{|c|}{ Violence Behaviours and Violence Classification } & \multicolumn{5}{|c|}{ STAXI-II (Anger Expression) } \\
\hline & $\begin{array}{l}\text { Violence } \\
\text { Behaviours }\end{array}$ & Offenders & $\begin{array}{l}\text { Indirect } \\
\text { Victims }\end{array}$ & $\begin{array}{l}\text { Direct } \\
\text { Victims }\end{array}$ & Witnesses & Anger-Out & Anger-In & $\begin{array}{l}\text { Anger-Control } \\
\text { Out }\end{array}$ & $\begin{array}{l}\text { Anger- } \\
\text { Control In }\end{array}$ \\
\hline Violence & 1.00 & $0.85^{*}$ & $0.44 *$ & $0.51 *$ & $0.53^{*}$ & 0.09 & $-0.38^{*}$ & -0.16 & -0.09 \\
\hline Behaviours & & & & & & & & & \\
\hline Offenders & - & - & $0.53 *$ & $0.66^{*}$ & $0.66^{*}$ & 0.26 & -0.23 & -0.26 & -0.18 \\
\hline Indirect Victims & - & - & - & $0.64 *$ & $0.48^{*}$ & $0.37 *$ & 0.06 & -0.20 & 0.10 \\
\hline Direct Victims & - & - & - & - & $0.78^{*}$ & $0.41 *$ & -0.14 & -0.02 & -0.05 \\
\hline Witnesses & - & - & - & - & - & 0.16 & $-0.38 *$ & -0.23 & $-0.36^{*}$ \\
\hline Anger-Out & - & - & - & - & - & - & $0.64^{*}$ & -0.05 & 0.16 \\
\hline Anger-In & - & - & - & - & - & - & - & 0.14 & 0.23 \\
\hline $\begin{array}{l}\text { Anger-Control } \\
\text { Out }\end{array}$ & - & - & - & - & - & - & - & - & $0.65^{*}$ \\
\hline
\end{tabular}


As for test-retest reliability, three indices showed high reliability, including violence behaviours and violence classification, $r_{s}(30)=0.71$, and CTC-YS, $r_{s}(30)=0.90$, at statistical significance, $p<.05$. Nevertheless, the STAXI-II scale designed to assess anger expression did not show good test-retest reliability (Table 6).

Table 6. Spearman rho test-retest reliability coefficients

\begin{tabular}{llc}
\hline Scales & Spearman Correlation & p value \\
\hline Violence Behaviours and Classification & 0.71 & .001 \\
STAXI-II (Anger) & 0.45 & .09 \\
CTC-Youth Survey & 0.90 & $<.001$ \\
\hline
\end{tabular}

\section{Discussion}

Behavioural and social scientists who study youth violence need measures and approaches that are culturally appropriate and that generate reliable and valid results. Valid and reliable assessment is needed in order to screen violence behaviours and violence consequences for diverse ethnic groups. This continues to be important in the development of treatment programmes and violence prevention services (Cervantes, Duenas, Valdez, \& Kaplan, 2006). Unfortunately, there are few published research reports that have measured youth violence related to psychological disorders (anger expression) in Asians (Chen \& Astor, 2010; Lim, Day, \& Casey, 2011). Moreover, there are no studies assessing reliability and validity of psychometric scales in all domains (school, peer and individual, community, and family) with CTC-YS in Asians. Additionally, this is the first study on Thai youths to reveal strong reliability and validity of self-administered questionnaires associated with protective and risk factors through juvenile delinquencies, violence behaviours, violence classification and anger expression.

Overall self-report measures showed high internal consistency, test-retest reliability and validity. Similarly, CTC-YS studies in the US revealed high reliability and validity through all risk and protective factors for males and females within five racial and ethnic groups (White, African American, Native American, Hispanic, Asian and Pacific Islander) (Glaser et al., 2005; Hawkins, Van Horn, \& Arthur, 2004). The STAXI-II has demonstrated good reliability and construct validity across different ethnic samples, in China (Bishop \& Quah, 1998), in the US (Hispanic and Non-Hispanic) (Culhane \& Morea, 2010), and in Singapore (Diong \& Bishop 1999; Lim et al., 2011). Unfortunately, as far as we know, no previous reports have assessed validity and reliability of violence behaviours and violence classification in Asian countries.

The low correlation between Risk Behaviours from CTC-YS and violence behaviours with $r_{s}(30)=0.36$ was suggested, perhaps because the different self-administered questionnaires did not interpret the concept of violence behaviours in the same manner. Additionally, the results revealed high correlation within each domain. Across the domains, Peer-Individual domain showed strong correlation, $r_{s}(30)>0.70$, with Community, and with Family domains, also Community Domain strongly related to Family Domain. Similarly, the prior study found that peer factor was the most common cause of violence behaviours in middle-school students, followed by societal factors, individual factors, and family factors (Zimmerman et al., 2004). Nevertheless, the only social skills as protective factor on Pee-Individual domain showed low internal consistency reliability with alpha coefficients less than 0.6 that was inconsistent with Arthur et al. (2002). The internal consistency for social skills in US students (grade $\left.6^{\text {th }}, 8^{\text {th }}, 11^{\text {th }}\right)$ ranged from $0.56\left(11^{\text {th }}\right.$-grade) to $0.70\left(8^{\text {th }}\right.$-grade $)$ in a longitudinal study with a large sample (Arthur et al., 2002). Indeed, the Social Skills subdomain is designed to assess the potential for malleability and direct relevance for programs that promote social and emotional competence which may not be relevant for Thai youths.

The STAXI-II showed the highest overall internal consistency (Table 3), except for the Anger-In subscale which had only a moderate alpha coefficient $(\alpha=0.62)$. This was consistent with prior studies that have shown that all scales of the STAXI, except for Anger-In, had adequate reliability and validity for African, Hispanic, and European adolescents (11-16 years old) (Musante, Treiber, Davis, Waller, \& Thomposon, 1999; Reyes, Meininger, Liehr, Chan, \& Mueller, 2003) . With the violence behaviour scales, the findings revealed high item homogeneity with alpha coefficient more than 0.70 . The highest internal consistency were shown in offender subscales $(\alpha=0.94)$. Hence, the violence behaviours and violence classifications (offenders, witnesses, victims) are acceptable scales as good measurements for Thai culture although they were developed in Western cultures and have been used and assessed only in Western societies (Loeber et al., 2003). 
Test re-test reliability was good during two weeks periods on violence behaviours and violence classification, and CTC-YS, but STAXI-II which examined anger expression, did not show good re-test reliability, $r_{s}(30)=$ $0.45, p=.09$. Anger is a commonly expressed emotion throughout the course of one's life (Armstead \& Clark, 2002), so daily life circumstances may influence anger feelings leading to different results in the second test in two weeks later. Additionally, test-retest reliability decreases as the period between tests is increased (Welk, 2002).

Regarding the validity findings, the violence behaviours scale correlated strongly with all violence classification (offenders, indirect victims, direct victims, and witnesses), especially offenders. As expected, offenders had higher delinquent behaviours than non-offenders (Gelaye et al., 2008; Gudlaugsdottir, Vilhjalmsson, Kristjansdottir, Jacobsen, \& Meyrowitsch, 2004; Song, Singer, \& Anglin, 2000), and they also had a negative correlation with Anger-In expression as mentioned in several studies (Foley, Hartman, Dunn, Smith, \& Goldberg, 2002; Thomas \& Smith 2004). Interestingly, the intercorrelation between victim (direct and indirect) behaviours scale and Anger-Out scale were generally high. The possibility is individuals who frequently hold their anger in as victims or witnesses, may also frequently reach a "boiling point" at which they direct their anger outwardly (Foley et al., 2002).

Finally, this is the first study to reveal high validity and reliability of self-administered questionnaires, including risk and protective factor (individual-peer, family, school and community), violence behaviours and violence classification, anger expression in a sample of Thai male youth. Additionally, this study is able to provide a good quality self-reports for multiple assessments within one self-report with all information related to youth violence including negative emotions.

\section{Strengths and Limitations of the Study}

The main strength of this study was the fact that we provided data on the validity and reliability of measures of youth violence which were translated into Thai language. Whilst these measures have been used many times using English language, this is the first attempt to develop rigorous evidence for their future use in Thailand (or Thai communities in other countries). Given the relatively high prevalence of violence in certain sub-populations of Thailand, our valid and reliable measures will be of invaluable use to assess the impact of interventions aimed at reducing violence in Thailand. The main limitation of this study was the small sample sizes $(n=32)$ which was insufficient to analyse predictive validity by logistic regression and factor analysis. Several studies state that minimum sample sizes for factor analysis vary from 100 to 250 (see, for example, Cattell, 1978; Comrey \& Lee, 1973; Gorsuch, 1983). The fact that we did not have a truly random sample may question the generalizability of our findings, but our sample size still allowed the calculation of validity and reliability measures. One of the reasons for a relatively small sample size relates to the fact that we needed young men with violent behaviour, which is a sensitive issue and potentially reduces willingness to participate in such research. Nevertheless, Hackshaw (2008) pointed out that "there is nothing wrong with conducting well-designed small studies; they just need to be interpret carefully" (Hawckshaw, 2008, pp. 1143).

\section{Acknowledgements}

The authors wish to thanks a private technical college in Bangkok and a teacher in the college for providing facilities in the research, and they also would like to express their appreciation to participants for their valuable contribution to the study. Furthermore, the authors are highly grateful to Professor Charles D. Spielberger for granting permission for the STAXI-II to be used in the study.

\section{References}

Armstead, C. A., \& Clark, R. (2002). Assessment of anger expression in pre- and early-adolescent African Americans: Psychometric considerations. Journal of Adolescence, 25(4), 365-371. http://dx.doi.org/10.1006/jado.2002.0481

Arthur, M. W., Briney, J. S., Hawkins, J. D., Abbott, R. D., Brooke-Weiss, B. L., \& Catalano, R. F. (2002). Measuring risk and protection in communities using the Communities That Care Youth Survey. Evaluation $\begin{array}{llll}\text { and Program } & \text { Planning, } & \text { 197-211. }\end{array}$ http://dx.doi.org.ezproxy.csu.edu.au/10.1016/j.evalprogplan.2007.01.009,

Assanangkornchai, S., Pattanasattayawong, U., Samangsri, N., \& Mukthong, A. (2007). Substance use among high-school students in Southern Thailand: trends over 3 years (2002-2004). Drug Alcohol Dependence, 86(2-3), 167-174. http://dx.doi.org.ezproxy.csu.edu.au/10.1016/j.drugalcdep.2006.06.001 
Bauman, S., \& Summers, J. J. (2009). Peer victimization and depressive symptoms in Mexican American middle School Students: Including acculturation as a variable of interest. Hispanic Journal of Behaivoral Sciences, 31(4), 515-535. http://dx.doi.org/10.1177/0739986309346694

Bishop, G. D., \& Quah, S. H. (1998). Reliability and validity of measures of anger/hostility in Singapore: Cook \& Medley HO Scale, STAXI and Buss-Durkee Hostility Inventory. Personality and Individual Differences, $24,867-878$.

Cattell, R. B. (1978). The scientific use of factor analysis in behavioral and life sciences. New York: Plenum.

Centers for Disease Control and Prevention. (2003). Youth Risk Behavior Surveillance System (YRBSS): High School Questionnaire. Retrived November 1, 2010, from http:www/cdc.gov/nccdphp/dash/yrbs/2003/questionnaire.htm.

Centers for Disease Control and Prevention. (2010). Differences by sex in tobacco use and awareness of tobacco marketing-Bangladesh, Thailand, and Uruguay, 2009. Morbidity and Mortality Weekly Report, 59(20), 613-618.

Cervantes, R. C., Duenas, N., Valdez, A., \& Kaplan, C. (2006). Measuring violence risk and outcomes among Mexican American adolescent females. Journal of Interpersonal Violence, 21(1), 24-41. http://dx.doi.org/10.1177/0886260505281602

Chen, J. K., \& Astor, R. A. (2010). School violence in Taiwan: Examining how Western risk factors predict school violence in ann Asian culture. Journal of Interpersonal Violence, 25(8), 1388-1410. DOI:10.1177/0886260509354576

Comrey, A. L., \& Lee, H. B. (1973). A first course in factor analysis. New York: Academic Press.

Crick, N. R., \& Grotpeter, J. K. (1996). Children's treatment by peers: Victims of relational and over aggression. Development and Psychology, 8(2), 367-380.

Cronbach, L. J. (1951). Coefficient alpha and the internal structurre of tests. Psycometrika, 16(3), 297-334.

Culhane, S. E., \& Morea, O. F. (2010). Reliability and validity of the Novaco Anger Scale and Provocation Inventory (NAS-PI) and State-Trait Anger Expression Inventory-2 (STAXI-II) in Hispanic and non-Hispanic White student samples. Hispanic Journal of Behaivoral Sciences, 32(4), 586-606. http://dx.doi.org/10.1177/0739986310381458

Developmental Research and Programs. (1996). Communities That Care planning kit Seattle, WA: Author.

Diong, S. M., \& Bishop, G. D. (1999). Anger expression, coping styles, and well-being. Journal of Health Psychology, 4(1), 81-96.

Foley, P. F., Hartman, B. W., Dunn, A. B., Smith, J. E., \& Goldberg, D. M. (2002). The utility of the State-Trait Anger Expression Inventory with offenders. International Journal of Offender Therapy and Comparative Criminology, 46(3), 364-378. http://dx.doi.org/10.1177/0306624X02463009

Garcia-Leon, A., Reyes, G. A., Vila, J., Perez, N., Robles, H., \& et al. (2002). The aggression questionnaire: a validation study in student smaples. The Spanish Journal of Psychology, 5(1), 45-53.

Gelaye, B., Philpart, M., Goshu, M., Berhane, Y., Fitzpatrick, A. L., \& Williams, M. A. (2008). Anger expression, negative life events and violent behaviour among male college students in Ethiopia. Scandinavian Journal of Public Health, 36(5), 538-545. http://dx.doi.org/10.1177/1403494807086916

Ghos, S. N., \& Sharma, S. P. (2006). Trait anxiety and trait anger: A comparison of peptic ulcer and bronchial patients. Journal of Indian Academy of Applied Psychology, 32(2), 151-157.

Glaser, R. R., Van Horn, M. L., Arthur, M. W., Hawkins, J. D., \& Catalano, R. F. (2005). Measurement properties of the Communities That Care Youth Survey across demographic groups. Journal of Quantitative Criminology, 21(1), 73-102. http://dx.doi.org/10.1007/s10940-004-1788-1

Gorsuch, R. L. (1983). Factor analysis (2 $2^{\text {nd }}$ ed). Hillsdale, NJ : Lawrence Erlbaum.

Gudlaugsdottir, G. R., Vilhjalmsson, R., Kristjansdottir, G., Jacobsen, R., \& Meyrowitsch, D. (2004). Violent behaivour among adolescents in Iceland: a national survey. International Journal of Epidemiology, 33(5), 1046-1051. http://dx.doi.org/10.1093/ije/dyh190

Hawkins, J. D., Herrenkohl, T., Farrington, D. P., Brewer, D., Catalano, R. F., \& Harachi, T. W. (1998). A review of predictors of youth violence. In Serious and violent juvenile offenders: Risk factors and successful intervention, edited by Loeber, R. and Farrington, D. P., 106-146. Thousand Oaks: CA: Sage. 
Hawkins, J. D., Van Horn, M. L., \& Arthur, M. W. (2004). Community variation in risk and protective factors and substance use outcomes. Prevention Science, 5(4), 213-220.

Krug, E. G., Mercy, J. A., Dahlberg, L. L., \& Zwi, A. B. (2002). The world report on violence and health. Lancet, 360(9339), 1083-1088.

Le, T. N., Monfared, G., \& Stockdale, G. D. (2005). The relationship of shool, parent, and peer contextual factors with self-reported delinquency for Chinese, Cambodian, Laotian or Mien, and Vietnamese Youth. Crime \& Delinquency, 5l(2), 192-219. http://dx.doi.org/10.1177/0011128704273472

Lennings, C. J., Copeland, J., \& Howard, J. (2003). Substance use patterns of young offenders and violent crime. Aggressive Behavior, 29(5), 414-422. http://dx.doi.org/10.1002/ab.10048

Lim, L., Day, A., \& Casey, S. (2011). Social cognitive processing in violent male offenders. Psychiatry, Psychology and Law, 18(2), 177-189. http://dx.doi.org/10.1080/13218711003739490

Lindqvist, J. K., Daderman, A. M., \& Hellstrom, A. (2003). Swedish adaptations of the Novaco Anger Scale-1998, the Provocation Inventory, and the State-Trait Anger Expression Inventory-2. Social Behavior and Personality, 31(8), 773-788.

Loeber, R., Farrington, D. P., Stouthamer-Loeber, M., Moffitt, T. E., Caspi, A., White, H. R., \& et al. (2003). The development of male offending : Key findings from fourteen years of the Pittsburgh Youth Study. In T. P. Thronberry \& Krohn, M.D. (Eds). Taking stock of delinquency: An overview of findings from contemporary longitudinal studies (pp. 91-136). New York: Kluwer/Plenum.

McDermont, M. N., \& Palchanes, K. (1994). A literature review of the critical elements in translation theory. Image, 26(2), 113-117.

Miguel-Tobal, J. J., Casado, M. I., Cano-Vindel, A., \& Spielberger, C. D. (2001). Inventario de Expresion de Ira Estado-Rasgo: STAXI-2 [State-Trait Anger Expression Inventory-2]. Madrid, Spain: TEA Edictiones.

Muller, C. J., Bongard, S. J., Heiligtag, U. J., \& Hodapp, V. J. (2001). Das State-Trait-Argerausdrucks-Inventar (STAXI) in der klinischen Anwendung: Reliabilitat und faktorielle Validitat [ The State-Trait Anger Expression Inventory (STAXI) in clinical application : Reliability and factorial validity]. Zeitschrift fur Klinische Psychologie und Psychotherapie : Forschung und Praxis, 30(3), 172-181.

Musante, L., Treiber, F. A., Davis, H. C., Waller, J. L., \& Thomposon, W. O. (1999). Assessment of self-reported anger expression in youth. Assessment, 6(3), 225-233.

Novaco, R. W., \& Taylor, J. L. (2004). Assessment of anger and aggression in male offenders with $\begin{array}{llll}\text { developmental disabilities. } & \text { Psychological } & \text { Assessment, } & \text { 16(1), }\end{array}$ http://dx.doi.org/10.1037/1040-3590.16.1.42

Orapins, P., \& Kelder, S. (1995). Students for Peace Project. Second student evaluation. Houston TX: University of Texas Health Science Center at Houston, School of Public Health (Unpublished).

Pollard, J. A., Hawkins, J. D., \& Arthur, M. W. (1999). Risk and protection: Are both necessary to understand diverse behavioral outcomes in adolescence? Social Work Research, 23(3), 145-158.

Reyes, G. A., Meininger, J. C., Liehr, P., Chan, W., \& Mueller, W. (2003). Anger in adolescents, sex, ethnicity, age differences, and psychometric properties. Nursing Research, 52(1), 2-11.

Reza, A., Krug, E. G., \& Mercy, J. A. (2001). Epidemiology of violent deaths in the world. Injury Prevention, 7(2), 104-111.

Ruangkanchanasetr, S., Plitponkarnpim, A., Hetrakul, P., \& Kongsakon, R. (2005). Youth risk behavior survey: Bangkok, Thailand. The Journal of Adolescent Health, 36(3), 227-235. http://dx.doi.org/10.1016/j.jadohealth.2004.01.013

Smith, C., \& Krohn, M. D. (1995). Delinquency and family life among male adolescents: The role of ethnicity. Journal of Youth and Adolescence, 24(1), 69-93.

Song, L. Y., Singer, M. I., \& Anglin, T. M. (2000). The relationship between children's threats of violence and violent behaivors. Archives of Pediatrics \& Adolescent Medicine, 154(8), 785-790.

Spielberger, C. D. (1999). State-Trait Anger Expression Inventory-2: Professional manual. Lutz, FL: Psychological Assessment Resources.

Taylor, R. (1990). Interpretation of the correlation coefficient: A Basic Review. Journal of Diagnostic Medical Sonography, 6(1), 35-39. 
Thomas, S. P., \& Smith, H. (2004). School connectedness, anger behaviors, and relationships of violent and nonviolent American youth. Perspective in Psychiatric Care, 40(40), 135-148.

Thornberry, T. P., Lizotte, A. J., Krohn, M. D., Farnworth, M., \& Jang, S. J. (1991). Testing interactional theory: An examination of reciprocal causal relationships among family, school, and delinquency. Journal of Criminal Law and Criminology, 82(1), 3-35.

Vocational Education Commission. (2010). College in Office of Vocational Educational Commission. Bangkok, Thailand: Ministry of Education.

Welk, G. L. (2002). Physical activity assessment for health related research. Human Kinetics. Champaign, IL.

Whitlock, J. L., \& Hamilton, S. F. (2003). The role of youth surveys in community youth development initiatives. Applied Development Science, 7, 39-51.

Zimmerman, M. A., Morrel-Samuels, S., Wong, N., Tarver, D., Rabiah, D., \& White, S. (2004). Guns, gangs, and gossip an analysis of student essays on youth violence. The Journal of Early Adolescence, 24(4), 385-411. http://dx.doi.org/10.1177/0272431604268551

\section{(c)) EY}

This work is licensed under a Creative Commons Attribution 3.0 License. 